history of autoimmune disease at the time of initiation of $\mathrm{CPI}$ treatment. One patient developed arthritis 8 weeks after the completion of anti-CTLA-4 antibody treatment. Two patients were receiving anti-PD-1 antibody when they developed arthritis. Patient 2 continued to receive anti-PD-1 antibody despite of arthritis-irAE while patient 3 discontinued anti-PD-1 antibody due to arthritis-irAE. The pattern of arthritis was symmetric polyarthritis involving small and large joints. Patient 1 had a positive rheumatoid factor (unknown baseline) and patient 3 had a positive ANA (known positive prior to CPI treatment). All patients were treated with anti-IL-6R antibody, which was well tolerated. All patients experienced a $40-100 \%$ reduction in global assessment, swollen joint count, and tender joint count, and these effects were maintained for up to 15 months of treatment (Figure 1). As of December 2016, all patients were alive; one patient was in complete remission and two patients had experienced progression of their melanoma. Conclusions: These three cases suggest that anti-IL-6R antibody is an effective alternative to TNFi for the treatment of arthritis-irAE.

Acknowledgements: None

Disclosure of Interest: None declared

DOI: 10.1136/annrheumdis-2017-eular.6504

\section{FRI0605 THE USE OF HAND PERFUSION SCINTIGRAPHY TO ASSESS RAYNAUD'S PHENOMENON ASSOCIATED WITH HAND-ARM VIBRATION SYNDROME}

K.A. Lee ${ }^{1}$, H.W. Chung ${ }^{2}$, S.-H. Lee ${ }^{1}$, H.-R. Kim ${ }^{1} .{ }^{1}$ Internal Medicine; ${ }^{2}$ Nuclear Medicine, Konkuk University Medical Center, Seoul, Korea, Republic Of

Background: Raynaud's phenomenon (RP) is a prominent manifestation of handarm vibration syndrome (HAVS). Previous studies have evaluated the diagnostic validity and characteristics of hand perfusion scintigraphy. However, no study to date has classified or differentiated the findings of this technique based on the aetiology of RP.

Objectives: This study aimed to evaluate the hand perfusion scintigraphic features of hand-arm vibration syndrome (HAVS) and to compare these with the features of primary and secondary Raynaud's phenomenon (RP) associated with connective tissue disease (CTD).

Methods: Hand perfusion scintigraphy was performed in 57 patients with primary RP, 71 patients with HAVS-related RP, and 36 patients with CTD-related RP. We calculated 6 ratios by using the time-activity curve and static blood pool images, the chilled to ambient hand and wrist ratios of the first peak height, initial slope, and blood pool uptake. We analysed 3 morphologic characteristics: slow progress pattern, paradoxically increased uptake pattern in the time-activity curve, and the inhomogeneous radioactivity uptake in the blood pool image.

Results: All of the 71 patients with HAVS-related RP were mine workers. The onset of RP after exposure to vibration was at $21.8 \pm 7.3$ years, with $26.3 \pm 7.0$ years of vibration exposure time. The chilled to ambient hand ratios of the first peak height and the initial slope were significantly lower in patients with HAVS-related occupational RP than in patients with primary RP. The presence of a paradoxically increased uptake pattern was significantly lower in HAVS than in primary RP.

Table 1. Comparison of the 6 quantitative variables of patients with Raynaud's phenomenon

\begin{tabular}{llcccc}
\hline Parameter & & HAVS & Primary RP & CTD & P value \\
\hline First peak height ratio & Hand & $0.90 \pm 0.89^{\mathrm{c}}$ & $1.50 \pm 1.50^{\mathrm{c}}$ & $1.03 \pm 1.12$ & $0.034^{\mathrm{a}}$ \\
& Wrist & $0.72 \pm 0.31$ & $0.87 \pm 0.57$ & $0.80 \pm 0.46$ & $0.161^{\mathrm{a}}$ \\
Initial slope ratio & Hand & $0.75 \pm 0.63^{\mathrm{d}}$ & $1.43 \pm 1.26^{\mathrm{d}}$ & $1.06 \pm 1.29$ & $0.002^{\mathrm{a}}$ \\
& Wrist & $0.87 \pm 0.83$ & $0.87 \pm 0.71$ & $0.84 \pm 0.86$ & $0.981^{\mathrm{b}}$ \\
\multirow{3}{*}{ Blood pool uptake ratio } & Hand & $0.85 \pm 0.39$ & $1.10 \pm 0.72$ & $0.87 \pm 0.67$ & $0.071^{\mathrm{a}}$ \\
& Wrist & $0.72 \pm 0.18$ & $0.73 \pm 0.40$ & $0.73 \pm 0.24$ & $0.982^{\mathrm{b}}$ \\
\hline
\end{tabular}

Data are presented as mean \pm standard deviation. HAVS: hand-arm vibration syndrome; CTD: connective tissue disease. ${ }^{a}$ Significant using analysis of variance (ANOVA). ${ }^{\text {b }}$ Significant using Welch test. ${ }^{\mathrm{C}}$ Primary $>$ HAVS $\left(P=0.015\right.$ by multiple comparisons), ${ }^{\mathrm{d}}$ Primary $>$ HAVS $(P=0.001$ by multiple comparisons)

Table 2. Comparison of presence of the 3 scintigraphic characteristics in the chilled hand of the patients

\begin{tabular}{lcccc}
\hline Characteristics & $\begin{array}{c}\text { HAVS } \\
(\mathrm{n}=71)\end{array}$ & $\begin{array}{c}\text { Primary RP } \\
(\mathrm{n}=57)\end{array}$ & $\begin{array}{c}\text { CTD } \\
(\mathrm{n}=36)\end{array}$ & P value \\
\hline Slow progression pattern & $61(86.0)$ & $51(89.5)$ & $32(88.9)$ & 0.809 \\
Inhomogenous radio-activity uptake pattern & $17(24.0)$ & $18(31.6)$ & $8(21.2)$ & 0.513 \\
Paradoxically increased uptake pattern & $15(19.7)^{\mathrm{a}}$ & $27(43.9)^{\mathrm{a}}$ & $10(27.8)$ & 0.012 \\
\hline
\end{tabular}

Data are presented as number (\%). HAVS: hand-arm vibration syndrome; CTD: connective tissue disease. a Primary > HAVS $(\mathrm{P}=0.004)$ on the basis of Chi-square test.

Conclusions: There were significant differences in hand perfusion scintigraphic features between primary RP and HAVS. These results suggest that the underlying pathophysiology of the two diseases differs; thus, different criteria might be applied for their evaluation

References:

[1] Palmer KT, Bovenzi M. Rheumatic effects of vibration at work. Best Pract Res Clin Rheumatol 2015;29:424-39.

Acknowledgements: The author(s) received no financial support for the research, authorship, and/or publication of this article.

Disclosure of Interest: None declared

DOI: 10.1136/annrheumdis-2017-eular.1505

\section{FRI0606 CHARACTERISTICS AND TREATMENT OF NEW ONSET} ARTHRITIS AFTER CHECKPOINT INHIBITOR THERAPY

L.A. Christ ${ }^{1}$, S. Mönch ${ }^{1}$, S. Hasmann ${ }^{1}$, I. Goldscheider ${ }^{2}$, M. Heppt ${ }^{2}$,

C. Berking ${ }^{2}$, F. Berger ${ }^{3}$, C. Dechant ${ }^{1}$, A. Skapenko ${ }^{1}$, H. Schulze-Koops ${ }^{1}$

J. Leipe ${ }^{1}$. ${ }^{1}$ Division of Rheumatology and Clinical Immunology, Department of Internal Medicine IV, University of Munich; ${ }^{2}$ Department of Dermatology and Allergology; ${ }^{3}$ Department of Radiology, University of Munich, Munich, Germany

Background: The recent introduction of biologic agents targeting immunologic checkpoints (immunologic checkpoint inhibitors $(\mathrm{ICI})$ ) established immunotherapy as a highly effective cancer therapy. $\mathrm{ICl}$ that trigger an anti-tumor response by activation of $T$ cells, may also cause immune-related adverse events (irAEs). Characterization of rheumatic adverse events such as arthritis and data on treatment of irAEs are scarce.

Objectives: To characterize patients with new-onset arthritis under $\mathrm{ICl}$ therapy and to assess the efficacy and safety of treatment that aimed to balance anti-tumor and anti-inflammatory therapy.

Methods: In this prospective observational study, patients with melanoma receiving $\mathrm{ICl}$ therapy who experienced arthralgias were evaluated for the presence of musculoskeletal inflammation. Data on demographics, ICI regime, time of onset and response to therapy of musculoskeletal irAEs, imaging, joint count, CRP/ESR, and immune serology were collected. Further, response to anti-inflammatory therapies including NSAR, glucocorticoids (GC) and methotrexate was assessed. Results: Of 7 patients with arthralgias after initiation of $\mathrm{ICI}$ therapy, all had objective signs of musculoskeletal inflammation. Arthritis was demonstrated in 6 patients, 3 oligoarthritis (SpA pattern), 2 polyarthritis (RA pattern), 1 monoarthritis. PMR-like disease with typical ultrasound findings was evident in 1 case. The time from start of $\mathrm{ICl}$ therapy to onset of synovitis symptoms varied from 1 to 259 days without a timely association to other irAEs. Upon first visit in our clinic, CRP levels were elevated in 6 of the patients ( 5.5 to $107 \mathrm{mg} / \mathrm{l})$ while immune serology was positive only in one patient (high titer RF and ACPA). Interestingly, in this patient low RF and ACPA titers had been detected when she presented with arthralgias without synovitis five years prior. This patient developed highly active RA one day after the first infusion of nivolumab. Retrospective analysis of cancer staging imaging studies revealed good sensitivity for PET-CT in the detection of synovitis, as opposed to contrast-enhanced CT. The baseline mean overall disease burden (assessed by VAS for pain, $0-10$ ) was $7.6 \pm 0.8$ and was significantly reduced after 3 months of anti-inflammatory treatment to $1 \pm 1.4$. Initially, all patients were treated with systemic and four patients also with intraarticular GC. Four of 7 patients flared on GC treatment upon tapering and were given methotrexate. Remission was achieved in all and prednisolone could be tapered. Patients were followed for a median of 152 days, and no safety signal with regard to tumor reappearance was detected. Conclusions: All patients with arthralgias upon $\mathrm{ICl}$ therapy had arthritis or PMR-like disease suggesting a need for increased awareness for musculoskeletal irAE. Inflammatory manifestations were associated with high disease burden and not self-limiting. While GC therapy is effective, flares were frequent after tapering and, thus, potential side-effects including attenuation of the anti-tumor efficacy of $\mathrm{ICl}$ are a concern. This is the first report on the efficacy and safety of methotrexate as a GC-sparing agent in ICl-induced arthritis.

Disclosure of Interest: None declared

DOI: 10.1136/annrheumdis-2017-eular.6532

\section{FRI0607 LONG-TERM AND OPTIMIZATION OF INFLIXIMAB IN REFRACTORY UVEITIS ASSOCIATED TO BEHCET DISEASE. MULTICENTRE STUDY OF 100 PATIENTS}

L.C. Domínguez Casas $^{1}$, V. Calvo-Río ${ }^{1}$, E. Beltrán ${ }^{2}$, J. S-Bursón ${ }^{3}$,

M. Mesquida ${ }^{4}$, A. Adán ${ }^{4}$, M. Hernandez ${ }^{4}$, F. L-Longo ${ }^{5}$, M. H-Grafella ${ }^{6}$,

E. Valls ${ }^{7}$, L. M-Costa ${ }^{8}$, A. Sellas ${ }^{9}$, J. G-Serrano ${ }^{10}$, J. Callejas ${ }^{10}$, N. Ortego ${ }^{10}$,

J. Herreras ${ }^{11}$, A. Follonosa ${ }^{12}$, O. Maíz ${ }^{13}$, A. Blanco ${ }^{13}, I$. Torre ${ }^{14}$

C. F-Espartero ${ }^{15}$, V. Jovani ${ }^{16}$, D. Peitado ${ }^{17}$, D. Díaz-Valle ${ }^{18}$, E. Pato ${ }^{18}$,

C. F-Cid ${ }^{19}$, E. Aurrecoechea ${ }^{20}$, M. García ${ }^{21}$, M. Caracuel ${ }^{22}$, A. Atanes ${ }^{23}$

F. Francisco ${ }^{24}$, S. Insua ${ }^{25}$, S. González-Suárez ${ }^{26}$, A. S-Andrade ${ }^{27}$, L. Linares ${ }^{28}$,

F. Romero ${ }^{29}$, A. García ${ }^{30}$, R. Almodovar ${ }^{31}$, E. Minguez ${ }^{32}$, C. Carrasco $^{33}$,

E. Raya ${ }^{10}$, M. Alcalde ${ }^{34}$, C. F-Carballido ${ }^{35}$, F. Pagés ${ }^{36}$, M. González-Vela ${ }^{1}$

C. Fernández-Díaz ${ }^{1}$, N. Vegas-Revenga ${ }^{1}$, R. Demetrio-Pablo ${ }^{1}$,

M. González-Gay ${ }^{1}$, R. Blanco $1.1{ }^{1} H U M V$, Santander; ${ }^{2} \mathrm{H}$ Mar, Barcelona; ${ }^{3} \mathrm{H}$ Valme, Sevilla; ${ }^{4} \mathrm{H}$ Clinic, Barcelona; ${ }^{5} \mathrm{H}$ G-Marañón, Madrid; ${ }^{6} \mathrm{H}$ General; ${ }^{7} \mathrm{H}$, Valencia; ${ }^{8} \mathrm{H}$ Peset, Valencis; ${ }^{9} \mathrm{H}$ Vall d'Hebron, Barcelona; ${ }^{10} \mathrm{H} \mathrm{S}$ Cecilio, Granada; ${ }^{11}$ IOBA, Valladolid; ${ }^{12} \mathrm{H}$ Cruces, Bilbao; ${ }^{13} \mathrm{H}$, Donostia; ${ }^{14} \mathrm{H}$ Basurto, Bilbao: ${ }^{15} \mathrm{H}$ Móstoles, Madrid; ${ }^{16} \mathrm{H}$ General, Alicante: ${ }^{17} \mathrm{H} \mathrm{Paz} ;{ }^{18} \mathrm{H} \mathrm{S}$ Carlos, Madrid; ${ }^{19} \mathrm{H}$, Pontevedra; ${ }^{20} \mathrm{H}$, Torrelavega; ${ }^{21} \mathrm{H}$ Princesa, Madrid; ${ }^{22} \mathrm{H}$, Córdoba; ${ }^{23} \mathrm{HUAC}$, A Coruña; ${ }^{24} \mathrm{H}$ D Negrín, Las Palmas; ${ }^{25} \mathrm{H}$, Santiago Compostela; ${ }^{26} \mathrm{H}$ Cabueñes, Gijón; ${ }^{27} \mathrm{H}$ L Augusti, Lugo: ${ }^{28} \mathrm{H}$ Arrixaca, Murcia; ${ }^{29} \mathrm{~F} \mathrm{~J} \mathrm{Díaz;}{ }^{30} \mathrm{H} 12$ octubre; ${ }^{31} \mathrm{~F}$ Alcorcón, Madrid; ${ }^{32} \mathrm{H}$ Clínico, Zaragoza; ${ }^{33} \mathrm{H}$, Merida; ${ }^{34} \mathrm{H} \mathrm{S}$ Ochoa, Madrid; ${ }^{35} \mathrm{H}$ Elda, Alicante; ${ }^{36} \mathrm{H}$, Palencia, Spain

Objectives: To assess the long term efficacy and optimization of Infliximab (IFX) in refractory Uveitis of Behçet Disease (BD)

Methods: Multicentre study of Uveitis associated-BD refractory to conventional immunosupressive drug. Ocular inflammation was evaluated with "SUN criteria" (Am J Ophthalmol 2005;140:509-516) and the macular thickening with OCT. Results are expressed as mean $\pm \mathrm{SD}$ or median [IQR] (comparison, Wilcoxon test) 